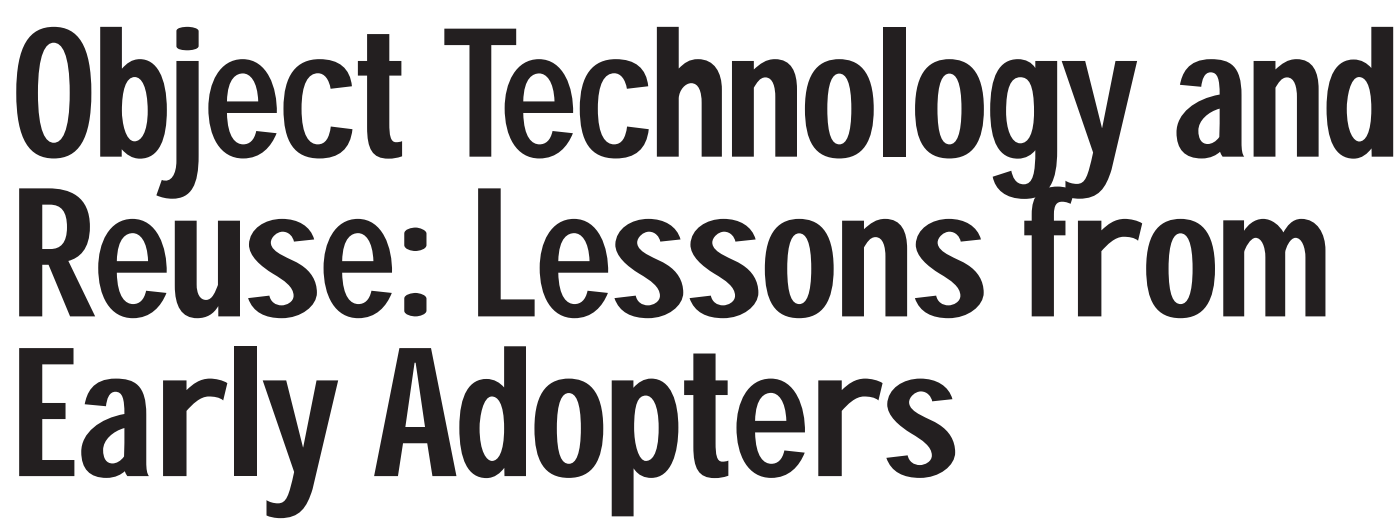

Four longitudinal case studies illustrate the costs and risks of early 00 adoption, including the diffic ulty of achieving systematic reuse in practice. The authors recommend general strategies and specific tactics for overcoming adoption barriers.

Robert G. Fichman Boston College

Chris F. Kemerer University of Pittsburgh

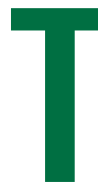

he recent commercialization of object-oriented software process technologies has been driven by pragmatic desires to increase productivity, shorten cycletimes, enhance maintainability and extensibility, and more fully satisfy user requirements. A lthough an organization's transition to $\mathrm{OO}$ typically centers on the use of an 00 language such as C ++or Smalltalk, other changes are also necessary if expected benefits are to be realized. These changes include new approaches to analysis and design, greater use of iterative/incremental development, and-perhaps most crucial-an increased emphasis on component reuse.

The image of developers assembling applications from existing components-rather than building them from scratch - has been a central part of the 00 vision since it emerged as a commercially viable technology in the late 1980s. ${ }^{1}$ Besides potentially increasing productivity and reducing cycletime, thereuse of proven components (especially black-box reuse) should reduce the maintenance burden and lead to more reliable and efficient systems. ${ }^{2}$

Although adopting a new software process technology is rarely easy, the early adoption of complex, framebreaking technologies such as 00 is likely to be particularly difficult and risky. In a previous article, we used innovation diffusion and economic theories to develop a two-dimensional framework that identified adoption barriers at the organization- and communitywide levels. ${ }^{3}$ The sidebar "W hat Drives Innovation Adoption?" describes some of our conclusions.

In 1992, we initiated four case studies of early 00 adopters, which we continued until 1996. These longitudinal case studies gave us a richer description of the actual challenges early adopters faced and helped us develop recommendations about how organizations can succeed with adoption in spite of potential barriers. O ur results are particularly significant because longitudinal case studies avoid the inevitable bias of most casestudies, in which results are analyzed retrospectively.

The cases illustrate lessons that should be of direct interest to organizations attempting to achievegreater reuse through 00 and those having to confront issues about software process technology adoption. All four case sites encountered learning barriers and barriers from immature technology; more important, all sites found it difficult to achieve systematic reuse.

\section{SITE OVERVIEWS}

Table 1 summarizes the characteristics of the four case-study sites. Each site met four criteria: They were implementing a fully 00 language; the project was staffed primarily by permanent employees, the adoption process was new enough for the ultimateoutcome to be unknown, and the organization seemed well positioned for adoption success as measured by funding, staffing, training, top management support, and so on. Figure 1 shows the timelines of 00 adoption activities for all four case-study sites. To gain this information, we conducted a series of interviews with staff at various levels, including developers, project managers, and other executives. Interviews typically lasted an hour, and we conducted on average seven sessions for each site. Between A pril 1992 and June 1993, we conducted interviews in person at each site. In August 1995, we conducted tel ephone interviews. In 0 ctober 1996, we made tel ephone contact to get a final update on the adoption status.

\section{Ener gyCo}

In M ay 1992, we visited EnergyC 0 , our first site. The company had begun implementing a Smalltalk development environment in fall 1989 to support the construction of two very large, complex systems-a Land $M$ anagement System to manage land leases and related rent and royalty payments and a Gas $M$ anagement System to manage gas accounting and so on. (All company, project, and system names are fictitious.) As Table 2 on page 49 shows, the primary trigger for this adoption was a division-wide reengineering effort, which stimulated EnergyC 0 's desire to use stateof-the-art tools to develop the systems that would support the new processes. As one manager put it, "We wanted to select the right platform for five to 10 years from now; we don't want to catch up, but to leapfrog 


\section{What Drives Innovation Adoption?}

In developing our framework on 00 adoption barriers, we first looked to research on innovation diffusionhow innovations spread through a population of potential adopters over time. This research was a natural starting point if you view $\mathrm{OO}$ as a software process engineering innovation. $\mathrm{H}$ owever, most research in this area fails to consider communitywide forces, which can determine whether technologies such as 00 will be sustained over a broad community of adopters.

For that reason, we decided our framework should have two dimensions: organization and community. For each, we considered the characteristics that facilitate or hinder adoption.

On the organization dimension, we identified five characteristics that innovation researchers have shown lead to adoption barriers.

- L ow relativeadvantage. The technology offers few advantages (in cost, functionality, and so on) over existing technologies.

- High complexity. The technology is relatively difficult to understand and use.

- Low compatibility. The technology is incompatible with existing methods. Either existing staff must be reskilled or new staff with the right skills must be hired.

- Low trialability. The technology is difficult to experiment with and implement incrementally and still get a positive net benefit.

- Low observability. Results and benefits are hard to observe and communicate.

We performed a conceptual analysis of 00 on these characteristics and concluded that the last four strongly applied. As a result, we expected that early adopters would experience difficulties, especially related to learning, in their initial attempts to implement object technologies.

Communitywide, we identified four characteristics that economists have shown lead to adoption barriers for new technologies.

- Prior technology drag. The technology must displace a well-entrenched prior technology.

- Irreversible investments. The technology requires large irreversible investments in products, training, and accumulated project experience.

- L ack of sponsorship. The technology has no strong entity to define the technology, set standards, and subsidize early adopters.

- Low expectations. The technology faces negative expectations about whether it will be pervasively adopted in the future.

We concluded that the first two characteristics strongly applied to 00 , indicating that a large community of committed $\mathrm{O} O$ adopters would be slow to emerge. As a result, we expected that early adopters would bear substantial additional costs arising from an extended period of technological immaturity.

Table 1. Characteristics of sites in the four case studies.

\begin{tabular}{|c|c|c|c|c|}
\hline & EnergyCo & BankCo & FinCo & BrokerCo \\
\hline Parent company & $\begin{array}{l}\text { US-based } \\
\text { international } \\
\text { energy company }\end{array}$ & $\begin{array}{l}\text { UK-based } \\
\text { retail } \\
\text { banking firm }\end{array}$ & $\begin{array}{l}\text { US-based international } \\
\text { financial services } \\
\text { company }\end{array}$ & $\begin{array}{l}\text { US-based international } \\
\text { financial services } \\
\text { company (subsidiary of FnCo) }\end{array}$ \\
\hline Business unit & $\begin{array}{l}\text { IT organization for } \\
\text { Exploration and } \\
\text { Production division }\end{array}$ & $\begin{array}{l}\text { Corporate IT } \\
\text { department }\end{array}$ & $\begin{array}{l}\text { IT organization for } \\
\text { Retail Marketing } \\
\text { Services division }\end{array}$ & $\begin{array}{l}\text { IT organization for } \\
\text { UK-based } \\
\text { brokerage division }\end{array}$ \\
\hline $\begin{array}{l}\text { IT development } \\
\text { budget in } 1993\end{array}$ & $\begin{array}{l}\$ 15 \text { million } \\
\text { (division) }\end{array}$ & $\begin{array}{l}£ 400 \text { million } \\
\text { (company) }\end{array}$ & Not available & $\begin{array}{l}£ 3.2 \text { million } \\
\text { (division) }\end{array}$ \\
\hline $\begin{array}{l}\text { IT development } \\
\text { staff in } 1993\end{array}$ & 80 (division) & $1,000+($ company) & 75 (division) & 50 (division) \\
\hline
\end{tabular}

current technology." Respondents generally view ed 00 as a powerful technology that enabled a "buildingblock approach" to software development. Prior to adopting $\mathrm{O} O$, EnergyCo had a fairly typical mainframe environment staffed with 80 IT professionals.
O ne of the most distinctive features of the company's approach was its willingness to substantially invest in the training and infrastructure to support 00 development. A sFigure 1 shows, in 1990 the company had put a team of 15 developers-all existing staff- 


\begin{tabular}{|c|c|}
\hline Characteristic & Description \\
\hline Prior environment & $\begin{array}{l}\text { Mainframes running IBM operating systems and databases (MVS, IMS, DB2), PL/1. Standard } \\
\text { development methodology based largely on Yourdon }\end{array}$ \\
\hline Primary adoption triggers & $\begin{array}{l}\text { Desire to use state-of-the-art technology to develop systems to support redesigned business processes; } \\
\text { strong recommendation of consultants }\end{array}$ \\
\hline Prior $\infty$ activities & None \\
\hline Approach to staffing and training & Existing staff ( 15 developers), extensive training, mentors \\
\hline Languages and tools & $\begin{array}{l}\text { Initially: ParcPlace Smalltalk, internally developed tools (modeler, GUl builder, query tool, RDB interface), } \\
\text { DB2, Unix, Windows, Banyan Vines }\end{array}$ \\
\hline Style of O development & $\begin{array}{l}\text { Eventually:ParcPlace Smalltalk and VisualWorks, Envy, Versant ODB, Unix, Windows, Banyan Vines. } \\
\text { Iterative; heavy use of prototyping; proprietary methodology initially, but later a combination of } \\
\text { CRC cards, Wirfs-Brock, and use cases }\end{array}$ \\
\hline Primary stated barriers/concerns & $\begin{array}{l}\text { Learning curve, absence/immaturity of tools, complexity of problem domain, managing iterative develop- } \\
\text { ment, finding and retaining } \bigcirc \text { staff, explaining } \bigcirc \text { benefits to senior management }\end{array}$ \\
\hline Primary mechanisms to promote reuse & Putting developers in same room; e-mail broadcasts \\
\hline C expenditures through 1995 & Over $\$ 10$ million, almost a third of which went for infrastructure tools \\
\hline $\begin{array}{l}\text { Status of } \infty \text { adoption as of each } \\
\text { date of contact }\end{array}$ & $\begin{array}{l}\text { May 1992: Piloting/enhancement of LMS planned for next } 12 \text { months, rollout to follow; } \infty \\
\text { considered technology of choice for new systems } \\
\text { June 1993: Implementation of about a third of LMS imminent; GMS under development; } \bigcirc \text { considered } \\
\text { technology of choice for new systems } \\
\text { August 1995: Selected portions of LMS implemented in phases over preceding two years; Packages now } \\
\text { the technology of choice; } O \text { intended only for especially complex problems } \\
\text { October 1996: LMS terminated due to cost of loading leases; portion of GMS implemented and } \\
\text { considered a success }\end{array}$ \\
\hline
\end{tabular}

through six weeks of 00 indoctrination. Several team members had then begun developing a series of infrastructure tools, including a CASE-like design tool, a graphical user interface devel opment tool, a relational database schema generator, a tool to manage a dynamic interface between Smalltalk and DB2, and an ad hoc query tool. O nly when thesetools were complete at the end of 1991 would they be ready to develop the LM S in earnest, which would becomethe focal project at this site. The G M S was initiated a few months later.

$O$ ver the next four years, the six-member LM S team encountered several setbacks. First they discovered the initial design architecture inherited from the original reengineering effort was inadequate. Then a pilot system, which they developed after reanalyzing requirements, also had a fundamentally flaw ed architecture. At the same time, most of the infrastructure tools were retired, although some were replaced with commercially available alternatives. The team then launched a second reanalysis, this time with use cases. Finally, after replacing key portions of their technical infrastructure, the team implemented small portions of the original system in phases. By August 1995, ambitions for the system had been scaled back considerably; it was unclear which remaining parts of the system (as originally envisioned) Energy Co would fund. When we last contacted them in O ctober 1996, EnergyCo had terminated the LM S project after determining that the cost to actually load up 20 million leases was prohibitive relative to benefits over the current land management system. However, a portion of the GM S to support gas trading was fully operational, and EnergyC 0 managers viewed it as a particularly innovative and w orthwhile application.
The G M S may have succeed ed because it did not have the unanticipated and prohibitive data entry cost involved with leases.

\section{BankCo}

A t our first visit in January 1993, BankCo had just finished developing the Process M odeler/G enerator, a small single-user system to design and generate applications that would support the rollout of new business processes in the branch offices. The company viewed PM/G specifically as a project to evaluate object technology.

As Table 3 shows, the primary trigger for 00 adoption was the company's goal to replaceall branch-based systems with modern workstations in a client-server architecture within fiveyears. BankCo's IT function was large (2,000+ IT professionals) and fairly traditional with a centralized mainframe-based architecture.

As Figure 1 shows, the PM /G development project began in M arch 1992 and continued for eight months. The external mentor mentioned in Table 4 helped establish management procedures and made it easier for the team to grasp 00 concepts and techniques. Although the original PM /G was never implemented as intended because of technical difficulties unrelated to 00 , a pilot project with a slightly revised PM /G was implemented within the IT function to track mortgage applications.

In 1993, the pilot project culminated in a detailed report describing the advantages of the 00 approach and recommending object technology as the strategic future direction. Partly because of this report, BankC o started three initiatives: It created an internal consulting group of the pilot team members, tasked with 


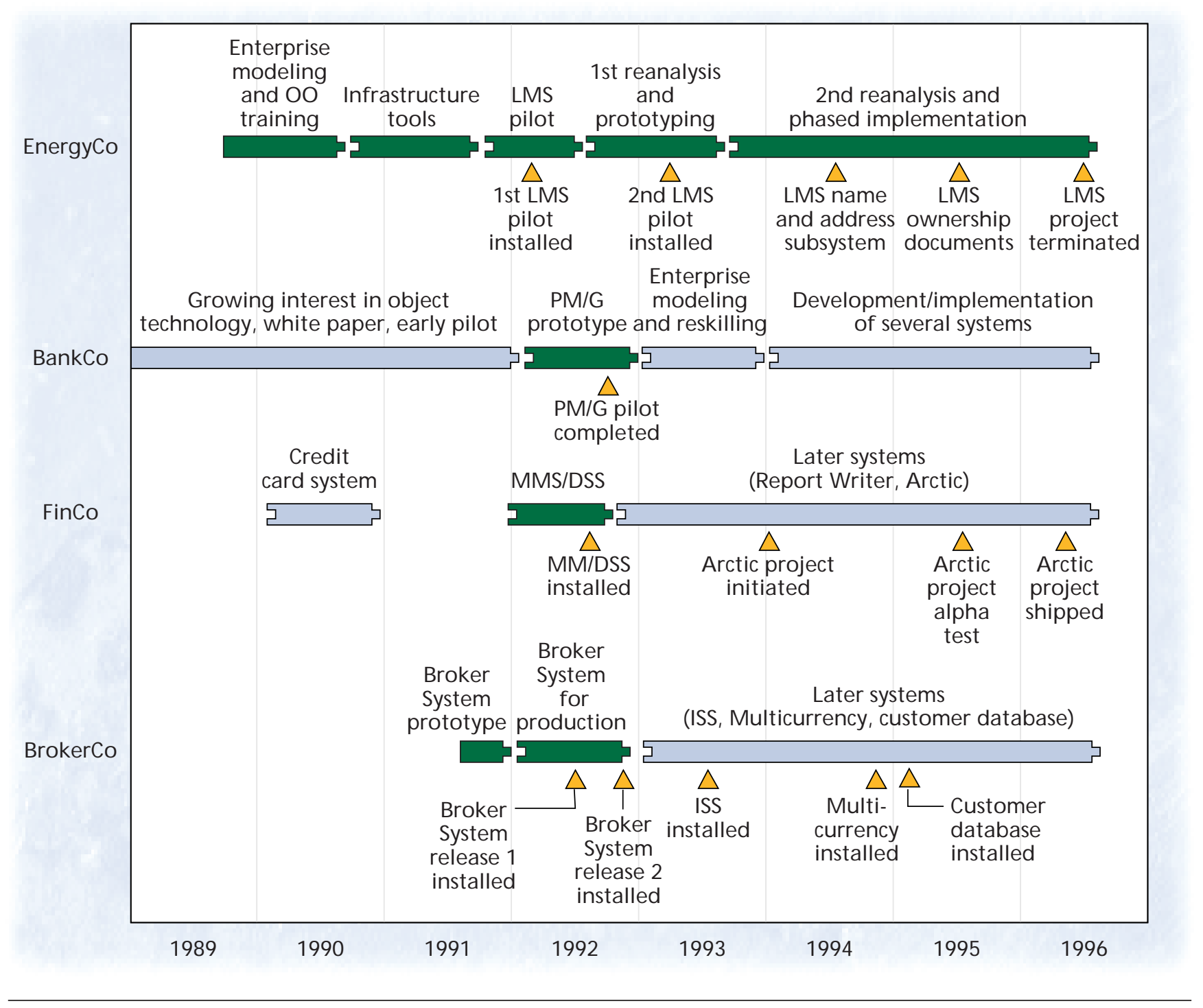

Figure 1. Timelines for 00 activities in the four case studies, including activities related to focal projects in the adoption of 00 (green lines) and activities related to 00 but not to focal projects (blue lines). The triangles identify project milestones.

investigating tools and "spreading the gospel of 00. ." It began a far-reaching program to retrain developers in the "brave new world of PCs, client-server, Windows, and object technology." It launched a large enterprise modeling effort, using 00 tools, to design systems that would support the "bank of the future."

In the ensuing three years, BankCo assembled a C ++ development organization of about 100 developershalf internal and half from outside- and set it to work delivering client-server applications using $\mathrm{C}++$, Windows NT, and Sequel Server. Although the company made steady progress delivering applications (completing about six significant projects), concerns lingered about the extent to which 00 principles (especially subclassing) were actually being follow ed and the extent to which reuse was being achieved. 0 ne manager observed,

I would have taken the original team and used it to concentrate expertise and build things up more slowly.
What we have ended up with is a lot of people who know a bit about 00 and actually apply some of it, and some who just know the words and don't bother.

BankCo also became interested in Visual Basic as an alternative to 00 and formed two factions-one advocating a "build for the long term" philosophy using $\mathrm{C}++$ and $\mathrm{OO}$, and another advocating a " build it fast" philosophy using Visual Basic.

\section{FinCo}

At our first visit in J une 1993, FinCo had completed a mass- mail system to support mark eting efforts, and tw 0 other 00 projects were underway. As Figure 1 shows, the company's first foray into object technology had occurred in 1990, with the development of a system to support the processing of correspondence from credit card customers. An executive in the Retail $M$ arketing Services division had hired a systems developer/consultant with extensive 00 -related academic 
Table 3. BankCo's 00 adoption background.

\begin{tabular}{|c|c|}
\hline Characteristic & Description \\
\hline Prior environment & Mainframes, IBM operating systems, Cobol, PL/1, Assembler, IMS, DB2 \\
\hline Primary adoption triggers & Interest in using latest technology to support widespread implementation of client-server in branch offices \\
\hline Prior $\infty$ activities & $\begin{array}{l}\text { Membership in Object Interest Group; white paper on object technology; help desk application built by } \\
\text { external contractor using rule-based system }\end{array}$ \\
\hline Approach to staffing and training & $\begin{array}{l}\text { Pilot project: Four existing staff members and one external mentor; some training provided } \\
\text { Later projects: Combination of retrained internal staff and external hires }\end{array}$ \\
\hline Languages and tools & $\begin{array}{l}\text { Pilot project: Intellicorp Kappa PC, DOS/Windows } \\
\text { Later projects: C++, Sequel Server, Windows NT }\end{array}$ \\
\hline Style of $\bigcirc$ development & $\begin{array}{l}\text { Pilot project: Iterative, prototyping, little formal analysis } \\
\text { Later projects: Iterative/evolutionary, prototyping, custom methodology based on OMT with elements of } \\
\text { Martin \& Odell, Wirfs-Brock, and use cases }\end{array}$ \\
\hline Primary mechanisms to promote reuse & $\begin{array}{l}\text { Pilot project: Training; very small team; informal communication } \\
\text { Later projects: Unknown }\end{array}$ \\
\hline Primary stated barriers/concerns & $\begin{array}{l}\text { Pilot project: Learning curve } \\
\text { Later projects: Learning curve; spreading } \infty \text { expertise too thinly; possible reversion to non-@ principles; } \\
\text { controversy over } \bigcirc \text { versus Visual Basic }\end{array}$ \\
\hline @ expenditures & For PM/G pilot: $£ 400,000$ \\
\hline $\begin{array}{l}\text { Status of } \infty \text { adoption as of each } \\
\text { date of contact }\end{array}$ & $\begin{array}{l}\text { January 1993: Initial pilot/evaluation completed; future use of } \infty \text { uncertain; further evaluation projects } \\
\text { planned and ongoing } \\
\text { August 1995: Several systems completed; } \bigcirc \text { the strategic direction for new distributed systems supporting } \\
\text { retail services } \\
\text { October 1996: } \infty \text { is technology of choice for distributed systems; research under way on how to bring some } \\
\text { of the benefits of } \bigcirc \text { to legacy systems }\end{array}$ \\
\hline
\end{tabular}

Table 4. FinCo's 00 adoption background.

\begin{tabular}{ll} 
Characteristic & Description \\
\hline Prior environment & Mainframe applications in Cobol; client-server applications based on Cand Windows \\
Primary adoption triggers & Belief that object technology provides a more robust platform for development of client-server applications \\
Prior OOactivities & One large system developed in 1990-91 but not implemented because of political infighting \\
Approach to staffing and training & All hired externally, most with extensive OO experience, all with at least some experience in Cor client-server \\
Languages and tools & Initially: C++, internally developed tools (foundation classes, GUl builder), SQL database, Windows \\
& Eventually: Objective C, internally developed tools (foundation classes, GUl builder), SQL database, NextStep \\
Style of OOdevelopment & Iterative; heavy use of prototyping; combination of Booch, OMT, and use cases \\
Primary stated barriers/concerns & Understanding of OOby top management; acceptance of OOby tool vendors and other third parties \\
Primary mechanisms to promote reuse & Weekly design reviews; new classes centrally reviewed \\
Total OOeffort through 1995 & 25+ person years [our estimate] \\
Status of OOadoption as of each & January 1993: MMS/DSS complete; technology of choice within RMS; use by other divisions uncertain \\
date of contact & August 1995: Multiple systems completed in RMS; Arctic under way, OOthe strategic direction companywide \\
& October 1996: Arctic shipped
\end{tabular}

training and industry experience. The developer assembled a team consisting of an 00 architect and seven other developers-most of whom had 00 and/or client-server experience. The RM S executive viewed the resulting credit card system as a success from a technical standpoint. However, because the system had been developed outside the main IT division, political battles over its control had led, in the executive's opinion, to the system's ultimate failure.

In 1992, the executive reassembled several of the original members of the credit card system staff, plus three new hires experienced in developing workstation applications, 00 programming, or both, and initiated an 00 project to develop a mass-mail system and a marketing decision support system (M M S/DSS).
Both were to be supported by information in a large customer database. The original technical architecture for the system was M SW indows and C ++ on the workstation side, and a relational database on the server side. Later, after the system was nearly complete, FinCo decided to port the systems to morepowerful $\mathrm{N}$ ext workstations and $\mathrm{O}$ bjective $\mathrm{C}$.

The initial version of M M S/DSS took eight months. The team developed the initial system in six months, and could reuse up to 85 percent of the code when FinCo decided to port the system to the $\mathrm{N}$ ext platform. As of June 1993, the system had been in production use for several months, some enhancements had been completed, and an additional series of enhancements were planned or under way. As Table 4 shows, the 


\section{Table 5. BrokerCo's 00 adoption background.}

\begin{tabular}{|c|c|}
\hline Characteristic & Description \\
\hline Prior environment & AS/400 \\
\hline Primary adoption triggers & $\begin{array}{l}\text { Arrival of new IS director after failure of several prior directors; visit by two primary players in } \\
\text { FnCo's } \bigcirc \text { efforts }\end{array}$ \\
\hline Prior $\infty$ activities & None at BrokerCo (but considerable at FinCo) \\
\hline Approach to staffing and training & Most hired externally; temporarily "borrowed" key developers from FnCo \\
\hline Languages and tools & $\begin{array}{l}\text { C++, internally developed tools (foundation classes, GUl builder), Sun servers running Sybase, } \\
\text { AS/400 database as repository }\end{array}$ \\
\hline Style of $\bigcirc$ development & Iterative; heavy use of prototyping; no formal methodology \\
\hline Primary stated barriers/concerns & $\begin{array}{l}\text { Not doing a formal analysis phase; not defining objects generically enough; not putting in } \\
\text { procedures to ensure reuse }\end{array}$ \\
\hline Primary mechanisms to promote reuse & None on initial projects; subsequently staffed an infrastructure group to institute a reuse program \\
\hline Total OOeffort through 1995 & $50+$ staff years (authors' estimate) \\
\hline \multirow[t]{2}{*}{ Status of $\infty$ adoption as of each date of contact } & $\begin{array}{l}\text { January 1993: Broker System installed; Investor Support System and Multicurrency projects under } \\
\text { way; } \infty \text { used for all new development; long-term transition plans uncertain }\end{array}$ \\
\hline & $\begin{array}{l}\text { August 1995/October 1996: several systems installed; COused for all new development; AS/400 } \\
\text { still heavily used }\end{array}$ \\
\hline
\end{tabular}

R M S executive was committed to using object technology for all major new projects in his area, although he was unsure of the long-term role for object technology within other divisions. By A ugust 1995, however, FinCo had established a fairly mature organization of developers delivering genuinely 00 applications in $\mathrm{C}+$ and $\mathrm{O}$ bjective $\mathrm{C}$, and had initiated A rctic, a very large project to develop consumer software that would support online trading.

Arctic encountered setbacks in 1995 and 1996, including missed internal shipping dates. Reasons cited include feature creep, difficulty getting required integration between workstations and back-end mainframes, and a culture clash between the 00 expert team and other divisions. Despite these setbacks, A rctic shipped in summer 1996.

\section{BrokerCo}

In January 1993, when we visited BrokerCo, the IT group had completed its first 00 application, Broker System, an information system to support the brokerage staff. The group was developing enhancements to that system and to somerelated systems. BrokerC o traditionally relied heavily on purchased packages and used traditional practices for developing any custom systems.

As Table 5 shows, two events in summer 1991 triggered BrokerCo's adoption of object technology. The first was the hire of a new systems devel opment director, who was given a mandate to create a more effective and responsive development organization. The second was a visit from two main players in FinCo's 00 activities, the RM S executive described earlier and the expert who had assembled the original 00 team. Together, they convinced the director that, given his desire to move to a client-server approach, he should strongly consider using object technologies.

Training was minimal; the initial Broker System team consisted of six externally hired professionals who either had experience developing 00 applica- tions using $\mathrm{C}++$ or had some other skill specific to the technical architecture (such as Sybase experience). The elapsed development time was about one year; about six staff-years were required for the initial version. 0 ne developer was devoted to maintaining and enhancing a tool kit inherited from FinC 0 , which contained classes to support basic system functions like data structures and GUI objects.

The director view ed the Broker System as successful. In 1993, five brokers were using the system daily, conducting some 500 transactions between them. Some scheduleslippage had occurred, in part because the director had set unrealistic deadlines as a motivational device. BrokerCo had also decided to skip a formal analysis phase and instead to rely entirely on rapid prototyping for requirements analysis. Consequently, the team did not uncover gaps in system functionality until user testing.

In January 1993, the director was still uncertain about the long-term role for object technologies. By A ugust 1995, however, BrokerC o had delivered multiple systems based on object technology (including an Investor Support System and support for multiple currencies) and 00 was the technology of choice for all new development. At our last contact in 0 ctober 1996, more systems had been implemented, and 00 remained the technology of choice for new systems.

\section{ADOPTION CHALLENGES}

All four case sites encountered considerable challenges in making the transition to 00 development. of these, three were pervasive.

\section{Organizational learning}

Respondents at all four sites noted the difficulty of grasping 00 concepts, and the steep learning curve in general:

Everyone would beworking with Smalltalk for a couple of months and then have a religious experience, 
... you have this tremendous awakening - like a curtain parting.-EnergyCo manager, 1992

A good C programmer does not turn into a good C ++ programmer. A structured analyst is not necessarily going to make a good 00 analyst. And an [expert] Cobol programmer is likely to become unbelievably demotivated when he is a lousy $\mathrm{C}++$ programmer for the first year. - FinCo executive, 1993

Is it better to hirefresh people, untainted by 18 years of whatever, or can you really retrain people? Wecan teach everyone here how to program in C, but it's the way of thinking [that's hard].-BrokerCo director, 1993

To ensure success with 00 , adopters must learn fundamental 00 principles, how to use commercial implementations of $\mathrm{O} O$ languages and supporting technologies, and how to reconfigureteam roles, structures, procedures, and incentives in light of the radical differences between 00 and conventional devel opment. ${ }^{4}$ In highly complex technologies such as 00 , the difficulty of organizational learning can be the primary barrier to successful adoption. ${ }^{5,6}$

$\mathrm{M}$ oreover, to truly grasp 00 principles, adopters need an extended period of learning by doing. As one FinCo developer put it, knowing what the words are and knowing what they mean aretwo different things. Respondents typically noted that, although classroom training and book learning was important, they did not truly understand 00 principles until they had had considerable hands-on experience- typically months of working closely with an experienced developer or mentor.

Thus, unless experienced 00 developers are hired from outside, learning will necessarily be timeconsuming and unpredictable. Energy $\mathrm{Co}$ and BankCo managers felt that the on-site assistance of one or two mentors was enough for a team of novice 00 programmers to learn by doing. $\mathrm{M}$ anagers at FinC 0 and BrokerCo disagreed; they felt they needed 00 developers with years of experience to build an adequate team. With experienced personnel carrying the primary burden of development, novice 00 programmers might begin with minor roles, growing into proficient developers over many months. When asked in 1993 to comment on having a team of novice 00 programmers carry the primary burden of development, a FinC o manager replied,

If managers were committed to it and were going to make people do it, they'd have some chance. But that's a recipe for frustration. You'd better be committed [enough] to haveyour first projects fail ... or show no net gain... and to stick with it for two or three years. Back in my consulting days, we came in on the second wave of lots of projects likethat. But at least management was committed enough to know it was the process [at fault].

For some developers, theburden of learning by doing was compounded by a lack of experience with other technologies typically used on 00 development projects. As one EnergyC o project leader explained in 1993,

It was a series of hurdles. Some people had never done anything on workstations, never used a mouse, never done anything in a graphical environment. I went to college late enough to be on somewhat familiar ground. O ther people seemed to have barriers.

FinCo and BrokerCo avoided this additional burden by almost exclusively employing people on 00 projects who were at least proficient in surrounding technologies, such as C and GUI- and workstationbased development. BankCo approached the problem another way for their pilot project. Initially they used $\mathrm{KappaPC}$, a high-level $\mathrm{O} O$ development languagethat insulated developers from many of the technological details of the underlying platform.

\section{Technological immaturity}

At all four sites, the costs of adoption, including learning-related costs, were magnified considerably by the absence or immaturity of tools to support 00 development:

We had thought Smalltalk and 00 were more ready for prime time. It was not so much the language itself, as the lack of a GUI, a code-management tool, a report writer, and so on. - EnergyC o manager, 1995

[Internal critics at FinC 0 ] go out and read articles and say show us the 4-to-1 or 10-to-1 development improvement. But a couple of pieces were missing. There were no good class libraries- we were writing our own-substantially for what we were doing. There are no real benefits in productivity to doing o 0 development unless you have some class libraries. It's fun and all but it isn't real productive until you have a code base that you can work on top of. And it hurt. - FinC o executive, 1993

Early adopters of network technologies like 00 incur considerable costs simply because they have joined a small and immature technological network. ${ }^{3,7} \mathrm{~W}$ ith our longitudinal approach, we can clearly document the nature of some of these costs. W hile 00 is, of course, more mature now than it was in the early 1990s, we believe our results can help organizations contemplating the early adoption of future technologies.

M ost early adopters are aware of immaturity as a general problem, but they fail to anticipate the com-
The costs of adoption were magnified considerably by the absence or immaturity of tools to support 00 development. 


Managers
also
complained
about the
extra costs
of software
development
from the lack
of supporting
tools.

plete array of necessary supporting tools and to establish the status of such tools in advance. This can be difficult given the tendency of vendors and other parties to exaggerate the variety and quality of tools and the degree to which they actually work well together. EnergyCo in particular was unpleasantly surprised by 00 's immaturity:

00 is advertised as a fast development tool, and as being more mature than it really is. Initially the learning curve was very steep. - EnergyC o manager, 1993

...we got the impression that lots of reusable components were available... that part of it turned out to be false.-EnergyCo developer, 1993

$M$ anagers at both FinC 0 and BrokerCo also complained about the extra costs of software development from the lack of supporting tools:

I'm a senior VP of financial services, and I have 70 or 80 people in this group. We're in another Windows class library evaluation-why? H ow is that possibly in [FinCo's] best interest? And N T compatibility. I don't want to think about this stuff. It's a waste of time.-FinCo executive, 1993

Probably 200 vendors could do a better job of maintaining and enhancing the toolkit...So we are really well out in front of the industry; [this] puts us in the position of doing things that don't add value. At the end of the day, our clients don't care about our toolkit.-BrokerCo manager, 1993

Three case sites-FinCo, BrokerCo, and Energy $\mathrm{Co}-$ devoted considerable resources to developing complementary tools, which they expected would one day be available commercially. FinCo and BrokerC 0 developed tools to support the creation of GUIs and to support integration with other technologies, such as relational database management systems. EnergyCo made a far greater investment in a portfolio of five infrastructure tools. It developed three of these tools- the schema generator, the dynamic interface manager, and the query tool-because of the perceived absence of an industrial-quality 00 database management system. (EnergyCo had planned to use a particular 00 database, but discovered that it did not integrate well with Smalltalk.) In the end, the company retired four of the five infrastructure tools. In some cases, changes in the technical approach made the tool unnecessary; in others, a commercial product became available that could do the same functions. As one manager put it,

We're in the business of building applications, not tools. M anagement doesn't want to pay to maintain those tools. - EnergyCo manager, 1993

This was a common sentiment at FinCo and BrokerCo as well.

\section{Elusive reuse}

$\mathrm{N}$ one of the four case sites reported reuse consistent with the 00 vision, in which developers deliver systems primarily by assembling existing components. When reuse did occur, it was at the most basic levels (string classes, containers, timeand date) or in the least leverageable forms (porting code, salvaging code during a system rewrite). Although these forms can be quitevaluable, an organization can achievethem without adopting 00 . L eading non-O 0 development environments-centered on RDBMS technology, for example- have for many years supplied built-in language functions and/or code generation options that cover much of the functionality in base classes (string manipulation and GUI screen painting, for example) and supporting tools likemodeling and querying. Some of the best ways to port code or salvage code during a subsequent rew rite are to use nonproprietary tools and good architectural design concepts like layering.

Using an 00 language on top of these approaches can certainly help-FinC 0 achieved its 85 percent code salvage this way-but the benefit is likely to be only incremental. 00 has the most potential for increased reuse as a technological enabler for black-box component reuse and for reuse through specialization. ${ }^{2}$

Interestingly, each site- and sometimes projects within a site- had different reasons for the failure of the 00 reuse vision. BankCo suspected that developers were using $\mathrm{C}++$ " as a better $\mathrm{C}$." Energy $\mathrm{C}$ o had different barriers:

We didn't havea librarian or someone who knew what all these methods are and what they do. I could be creating a method that does exactly the same thing somebody else's does...even though we have access to each other's code. We might call them different names and we might have a bit different way of doing it, but we're still doing the same thing.-EnergyCo developer, 1993

And BrokerCo had still different ideas:

Because of time pressures there was no up-front analysis and so no reuse; we had a prototype and were told to code it....Reuse is good but comes at a cost. People who have sold 00 talk about benefits but not the cost. N ow we see the costs of getting to a true 00 environment: doing a global business model, including future business plans.-BrokerCo developer, 1993

BrokerC o eventually made a strong commitment to 
invest in reuse three years after initial 00 adoption and created a new distributed systems development group with this in mind. N evertheless, hopes for actually achieving significant reuse were viewed as "a lofty goal."

A FinCo manager and architect we interview ed in 1993 was the most philosophical about the difficulty of achieving reuse:

It's hard to say what reuse really means. The objects that get reused tend to be generic, not domain specific-date, time, string classes. For domain specific, most objects get reused for major system revisions. $\mathrm{N}$ ot many objects are common across systems, when they are, say, a customer object, they have different behaviors, for example, inquiries versus updates. At the architectural level there is pretty consistent reuse - containers, strings, date, and time. Why not bundle all behaviors into a single common object? By the time you define all the behaviors the business will have changed. If you have to describe a car in excruciating detail-the engine, the ashtray, the trunk - you'll never get finished. D evelopers are not interested in doing this all-encompassing design up front. Why not build a base class when you first encounter an object, and add new behaviors to it? Going back to the car analogy, if they did the engine but you need the trunk, why bother? At some point you could have a separate group to pull components together and build a car. Until then, people have real deliverables to be done tomorrow. Engineers are pragmatic. If it does a fair amount of the work for them they will use it. But if it has to be maintained and "revved" it's not worth it. It sounds like [reuse] is the right way to do it, but it does not happen in practice.

O ne of the most telling observations is the tendency for many respondents to believe, at least starting out, that high levels of reuse come more or less automatically - that achieving systematic reuse is primarily a technical problem that 00 solves. This may partially explain the limited attention given to specific mechanisms for encouraging and enforcing reuse. Even after years of experience with 00 development, developers commonly had narrowly focused explanations for why less reuse was occurring than expected.

These results appear typical of organizations that first becomeinterested in reuseas a result of 00 adoption, rather than seeing a reuse-based development process as a substantial innovation in its own right. ${ }^{8}$ Although reuse scholars have argued for years that achieving systematic reuse requires a host of organizational and process changes that go beyond technology, ${ }^{9}$ it's not realistic to expect early adopters to know everything that might pertain to a technology they are adopting. Part of the burden of being an early adopter is the lack of understanding about the nature of the innovation being adopted, and the managerial practices required to achieve the desired results.

\section{LESSONS LEARNED}

We synthesized the experiences of the case sites into four key lessons, incorporating the wisdom of others in the 00 and reusefields where it was consistent with our case-study observations. Thelessons are specific enough to guide organizations considering immediate 00 adoption, but we also believe most can be extended to apply to other software process innovations (new languages, database technologies, methodologies, and so on) that make similarly radical demands on would-be adopters.

\section{Invest in or ganizational lear ning}

Sooner or later, most adopting organizations will have to educate new hires or retrain existing staff in the ways of $\mathrm{O} O$ development. Some estimates say about a year is required for an experienced procedural programmer to make the transition to 00 ; becoming an object designer or architect takes considerably longer. ${ }^{10}$

EnergyCo's approach to reskilling existing staff was exemplary. Team members, all with fairly standard mainframe skills starting out, were given six full weeks of training up front. $\mathrm{O} O$ novices first worked on the development of internal tools, which served as an extended training ground. The company then hired mentors to guide and review the team's efforts, thus providing an ongoing mechanism to facilitate training and experiential learning.

$\mathrm{N}$ ot all companies have the calendar time or resources to bring existing staff up the 00 learning curve. BankCo chose to get around this initially by adopting a simpler technology variant. FinCo hired all 00 expertise externally. Each strategy has its own pitfalls, how ever. A dopting a simpler technology variant is cheaper and less risky, but it is less flexible in the kinds of systems capabilities you can develop and is therefore harder to scale up to the larger systems that support core business processes. BankCo, even after proclaiming the virtues of $\mathrm{KappaPC}$ on their pilot project, felt compelled to choose the far more complex (and low level) $\mathrm{C}++$ for their 00 production development. Even so, adopting a variant can be a good strategy in some circumstances. O rganizations that feel they can develop needed systems adequately with existing technologies, but are concerned about keeping current with new technologies, might consider using simpler variants as a niche tool until the technology matures. Ultimately, if the technology does succeed and become dominant, even full-function technology variants will have become much simpler to use.

The second strategy - relying on externally hired personnel-may well bea necessary condition for the technical success of initial projects with reasonable size and
We synthesized the experiences of the case sites into four key lessons, incorporating other wisdom in the $\mathbf{0 O}$ and reuse fields where it was consistent with our case-study observations. 


Commercial
technologies
like 00
languages
are
incomplete
and must be
combined
with other
products,
services, and
expertise to
be useful.

complexity. H owever, because qualified staff are not always available or easy to identify when they are, not every organization can usethis strategy. Thereisa greater risk of invoking widespread skepticism and resentment among existing staff, and hence the transition may be more challenging in thelong run: As a BrokerCo project manager put it, "You need an insider to spread the gospel; we'revery much a group of outsiders."

\section{Develop a complete ar chitecture}

By "architecture" weinclude not only tangible products (languages, databases, middleware, CASE tools, class libraries, library managers) but also the organizational processes, structures, methodologies, and guidelines needed to effectively use those products in significant projects. An 00 language is of very little value to the typical IT organization unless it is bundled with developers who know how to use the language, a compatibleO 0 methodology, a workable approach to database access, and so on. As a BrokerCo project manager put it in a 1993 interview, "We had to rely on a mishmash of tools; wehad an 00 analysis model. H ow do you take that and get a database design?"

Thus, at least initially, commercial technologies like 00 languages are incomplete ${ }^{11}$ and must be combined with other products, services, and expertise to be useful. Eventually the market will begin to coalesce, key products will matureand beenhanced, and nearly complete and robust products and services will become available. But we're not there yet; no current off-theshelf product provides a complete solution to a variety of software development problems. O rganizations can acquire most of theindividual pieces of a complete 00 architecture off the shelf, although they must then integrate them into a coherent whole. But for the case-study adopters, many important components (automated object-modeling tools, production-quality class libraries for GUI development) simply were not available. This is part of the large cost adopters incur when they leave a large, mature network (like a third-generation environment), and join a small, immature one (like 00 ). O ngoing problems at EnergyC $\mathrm{C}$ with the link between Smalltalk and DB2 are a good illustration.

Somemajor architectural pieces weremissing. 0 ur database connection was inadequate. Wewereusing an open gateway with dynamic SQ $L$ to map objects onto relational structures...It is really difficult to do any functional kind of prototype when it takes eight minutes to retrieve something for users. - EnergyC o developer, 1993

BrokerCo also suffered costly (though not projectthreatening) gaps. M ost notably, they realized too late that they needed a formal 00 analysis phase to develop systems generic enough to support significant levels of subsequent reuse.
On the basis of our observations, we have identified four techniques that can lower the risk of an architectural collapse and make the development of a complete 00 architecture more manageable.

Hire an 00 architect. A qualified architect possesses knowledge and skill in 00 design principles, methodologies, and project management practices; alternative application architectures; the specifics of the technology set the organization intends to adopt; and the distinct elements of the problem domains in which systems are to be developed.

A rchitects also serve as the top layer in the threelevel structure commonly recommended for 00 development teams (architect/class designer/0 0 programmer), so they should also have leadership and communication skills. The case-study sites that had the smoothest transition either had an experienced architect on staff (FinC 0 ), or borrowed one for an extended period (BrokerCo).

An architect ensures that the blueprint on which all or subsequent efforts will depend is sound. At Energy $\mathrm{Co}$, theinability to recognize architectural inadequacies twice led to retrenchments. As an EnergyCo developer put it in a 1993 interview, "Wehad a brandnew technology, a brand-new modeling technique, and no single point of understanding for the wholething."

$M$ any roles other than architect can be developed internally, but an architect must be hired from outside. It is not feasible for existing staff to acquire the required knowledge to be an effective architect without years of hands-on experience in a variety of settings. ${ }^{10}$

Simplify architectural demands. Organizations should defer the development of large, complex, or mission-critical applications, if possible, and keep to well-understood application domains that play into 00 's strengths. We realize this advice can be difficult to follow; some of the most common reasons for early adoption are the desire to avoid building largenew systems with yesterday's technology (EnergyCo) and the desire to develop new kinds of systems with complexities thought to exceed the capabilities of existing tools (FinC 0 and BrokerCo). N evertheless, webelieve organizations must balance these immediate motivations with more fundamental long-term objectives, such as improving the odds of successfully assimilating a technology that could benefit many future projects.

Limit initial development. O rganizations should confine initial developments to niche areas defined narrowly enough to make assembling an adequate architecture off the shelf a more feasible undertaking. They can then move from niche to niche, letting the competencies and assets acquired in initial niches contribute to success in subsequent ones. 0 bject technology could be used for only early portions of the life cycle, selected application components (like the GUI), selected application types, or selected organi- 
zational purposes (like information retrieval). O ver time, the organization can merge islands of competence and tools into a more generalized architecture. Of course, any of these niche approaches initially curtails the benefits of 00 , but not as much as overly ambitious undertakings that ultimately fail.

Find proven architectural examples. O rganizations can aggressively network with other companies to find existing examples of complete architectures that have demonstrated success for problems of the same type and scale as the intended application environment. An extreme example is to attempt to locate and acquire a complete system similar to the intended application-source code and all-as a working reference model and design template. ${ }^{12}$ Granted, the probability of locating such a system may be low, but if successful, the payoff can be substantial.

Develop missing components. These components would be developed with the understanding that, sooner or later, they are likely to be replaced with commercial solutions. This approach is not quite as onerous as it may first appear, because these kinds of investments often have side benefits. The development of an internal process and tools is a comparatively safe way for novices to learn about object technology. Also, custom tools can be tailored to the needs of the local environment. At a time when an organization is al ready undergoing considerable pains to adapt to generic commercial tools, it can be advantageous to have some areas in which the burden of adaptation is placed on the tool.

\section{View reuse as separ ate}

Better support for a building-block approach to software development has been promoted as perhaps the single most important benefit of object technology. ${ }^{10}$ And for good reason: systematic reuse of this sort, unlike most advances in software development practice, may well beableto deliver thelong-sought-after 10x increase in programmer productivity-at least under the right circumstances. But although 00 provides some key technological enablers for systematic reuse, reuse consistent with this vision is rarely achieved: ${ }^{9}$

\footnotetext{
I have not experienced a great amount of reuse, and I don't know anyone who has. It's still too early to tell how effective reuse can be.... It requires a discipline and a support infrastructure. Putting all that in place requires a significant investment and a culture change. That takes a long time--BrokerCo director, 1995
}

00 is a great tool. But bringing it into a business is hard. It's very hard to get reuse in practice- especially with an extremely large group. We have a fairly small team, and it's hard enough to get reuse and get everyone on the same page.-EnergyCo developer, 1993
I think it's probably still too early to answer the reuse question for business objects. Is there a customer object at [FinCo] that we have reused under a number of applications or even an account object? $\mathrm{N}$ ope, not really. $\mathrm{N}$ ot nearly at that level._FinC o executive, 1993

The addition of technological enablers such as 00 does nothing to remove other reuse barriers. In fact, an emerging consensus in the reuse community is that the primary reuse barriers are nontechnical:8,13,14 a lack of incentive to build for reuse; no mature processes, methods, or tools for managing a large-scale reuse environment; and disagreement about what kinds of reuse are most promising (large- or fine-grained?) or about the best technical architectures for achieving reuse (pervasive or minimal use of inheritance?).

O ur case studies illustrate a number of common pitfalls to avoid when trying to establish systematic reuse: allowing project expediency to take priority over building for reuse; skipping 00 analysis and modeling; operating without a standardized reuse process; and failing to provide some kind of library function. In addition, a growing body of literature contains considerable positive wisdom on how to establish systematic reuse, much of it based on the experiences of leading companies with vigorous reuse programs. ${ }^{8,13}$ Although major investments are required to follow the advice in these sources, they need not be made all at once. Bertrand $M$ eyer has argued, for example, that organizations should concentrate on becoming good reuse consumers before they try to produce reusable components. ${ }^{2} \mathrm{M}$ artin Griss and $M$ arty Wosser describe an incremental approach to establishing reuse that has worked well at $\mathrm{H}$ ew lett-Packard. ${ }^{15}$

O rganizations adopting 00 because they believe it is an easy path to systematic reuse must ask themselves: Can our organization accommodate two major process innovations at the same time? If we had to choose between 00 and reuse- at least for the next several years - which would we pursue more vigorously?

An organization may decide to pursue systematic reuse as a primary innovation with 00 as a potential enabler, or it may choose to adopt 00 and view reuse as a "nice to have but not essential" element. M any of 00 's benefits-a more graceful paradigm for building GUIs, better support for multimedia and other applications that require complex data types, and better support for system interoperability-are not predicated on systematic reuse. For some organizations, these kinds of more incremental benefits may be sufficient to warrant 00 adoption.

\section{Sell adoption as process technology $R \& D$}

O ur case studies show that adopting a new technology like $\mathrm{OO}$ is rarely predictable and rarely has a

Our case
studies show
that adopting
a new
technology
like 00 is
rarely
predictable
and rarely
has a clear
and easily
achieved
result.

Our case studies show that adopting a new technology like 00 is rarely predictable has a clear and easily result. 


\begin{tabular}{l} 
Table 6. Advantages and disad \\
Advantages \\
\hline Enables new kinds of systems that exceed the capabilities of \\
existing technologies \\
Avoids continuing investment in new systems built around \\
possibly soon-to-be obsolete technologies (tomorrow's \\
legacy systems) \\
Moves general benefits (such as development productivity) \\
of using new technology forward in time \\
Grappling with the complexities of early vintages leads to a \\
deeper understanding of the technology \\
Use of the latest technologies makes it easier to attract and \\
retain talented staff, contributes to innovative capabilities \\
Recognized lead users receive positive press, and can \\
impact direction of technology as it develops
\end{tabular}

clear and easily achieved result. M any pitfalls await the early adopter. As Table 6 shows, the advantages of early adoption can easily be offset by the disadvantages. Yet when introduced, innovations like 00 are often promoted as something anyone can and should adopt to solve all problems in all situations. This sets management up with unrealistic expectations. What is actually adequate or even excellent progress in adoption and assimilation is often discounted or even discarded.

To help avoid setting up unrealistic expectations, adopters must counter the view among many senior executives that software process technologies can be inserted into an organization in a turnkey fashion. O ne way is to educate executives on the parallels between adopting new process technologies and other learningintensive activities with uncertain payoffs, such as new product development or $R \& D$. In this view, the early adoption of $O O$ is a multiyear $R \& D$ effort culminating in a staff, process, and technology infrastructure that can produce industrial-strength applications.

Of course, production applications must be developed along the way; they are essential to the learning process and to sustaining interest and funding. $\mathrm{N}$ evertheless, we believe that these projects should be view ed not just as an end in themselves, but also as the means by which effective processes and an infrastructure areinstituted, and they must bejudged accordingly.

If an organization does not havethe time, money, or expertise for $R \& D$ in process technology, it should delay 00 adoption until the technology has matured and knowledge barriers have been lowered-both natural products of technology evolution. ${ }^{6}$

O bject orientation and systematic reuse are prominent examples of attempts to improve the practice of software development through radical process innovation. Organizations contemplating adoption must balance the benefits of early adoption against the costs and risks we describe, and then develop an appropriate innovation strategy. The tactics we recommend to promote success as an early

\section{Disadvantages}

Higher risk of adopting a technology that never develops a large following (stranding)

Higher risk of having the approach congeal around a patched-together technical and process architecture

Much higher adoption and adjustment costs (technology evaluation, training, conversions, learning curve, and so on)

Can't benefit from accumulated wisdom about the technology, so risk of initial adoption failure and technology stigmatization is higher

Net loss of knowledge (trained personnel) across company borders

May be badly positioned to adopt a new and better class of technology about to emerge

adopter require considerable investments, and we realize that not all organizations have the resources or inclination to make such investments. For these, our advice is simple: Wait. O ver time, technologies destined for broad acceptance inevitably get simpler and easier to use; standards coalesce; complementary tools emerge that make it easier to assemble a complete architecture off the shelf; training gets better, cheaper, and more readily available; the supply of professionals already proficient in the technology increases; and wisdom accumulates in the industry at large about how and where to best apply the technology. Even among organizations that can afford substantial investments in process innovation, the benefits of waiting can often be compelling.

\section{Acknowledgments}

We thank the managers and developers at the case sites who gave their time so generously to support this research. We also thank the MIT Center for Information Systems R esearch for their financial support. We especially thank Jack R ockart for his encouragement and support of this work.

\section{References}

1. B. Cox, "Planning the Software Industrial Revolution," IEEE Software, N ov. 1990, pp. 25-33.

2. B. M eyer, O bject Success, Prentice Hall, Englewood Cliffs, N.J., 1995.

3. R. Fichman and C. Kemerer, "A doption of Software Engineering Process Innovations: The Case of 0 bject 0 rientation," Sloan M anagement R eview, N 0. 2, 1993, pp. 7-22.

4. R. Fichman and C. Kemerer, "O bject-O riented and Conventional Analysis and Design M ethodologies: Comparison and Critique," Computer, O ct. 1992, pp. 22-39.

5. P. Attewell, "Technology Diffusion and O rganizational Learning: The Case of Business Computing," O rganization Science, N o. 1, 1992, pp. 1-19. 
6. R. Fichman and C. Kemerer, "The Assimilation of Software Process Innovations: An O rganizational Learning Perspective," M IT Center for Information Systems R esearch W P 281, M anagement Science, to appear.

7. W. A rthur, "Competing Technologies: An O verview," in Technical Change and E conomic Theory, G. Dosi, ed., Pinter Pub., London, 1988.

8. M . Pittman, "Lessons Learned in M anaging O bject-O riented Development," IEEE Software, Jan. 1993, pp. 43-53.

9. M. Griss, "Software Reuse: From Library to Factory," IBM Systems ]., N o. 4, 1993, pp. 548-566.

10. T. Love, O bject L essons, SIGS Books, N ew York, 1992.

11. G. M oore, Crossing the Chasm, $\mathrm{H}$ arperBusiness, $\mathrm{N}$ ew York, 1992.

12. J. H ofman and J. Rockart, "A pplication Templates: Faster, Better, and Cheaper Systems," Sloan M anagement R eview, N o. 1, 1994, pp. 49-60.

13. W. Frakes and S. Isoda, "Success Factors of Systematic Reuse," IEEE Software, Sept. 1994, pp. 14-19.

14. H. M ili et al., "Reusing Software: Issues and Research Directions," IEEE Trans. Software Eng., June 1995, pp. 528-562.

15. M. Griss and M. Wosser, "M aking Reuse Work at H ewlett-Packard," IEE E Software, Jan. 1995, pp. 105107.

Robert G . Fichman is an assistant professor at the Wallace E. Carroll School of M anagement at Boston College. $\mathrm{H}$ is research interests include the management of technical innovation and software engineering management. Hereceived a BSE and an M SE from the $U$ niversity of $\mathrm{M}$ ichigan, and $\mathrm{a} \mathrm{PhD}$ in information technologies from the M assachusetts I nstitute of Technology's Sloan School of M anagement.

Chris F. Kemerer is the D avid M. R oderick chair in information systems at the U niversity of Pittsburgh. $\mathrm{H}$ is research interests include management and measurement issues in information systems and software engineering. H e received a BS in economics and decision sciences from the W harton School at the University of Pennsylvania and a PhD in systems sciences from Carnegie M ellon University.

Contact Fichman at Boston College, 354D Fulton $\mathrm{H}$ all, Chestnut Hill, MA 02167-3808; fichman@ bc.edu. or Kemerer at the U niversity of Pittsburgh, 278a M ervis H all, Pittsburgh, PA 15260; ckemerer@ katz.business. pitt.edu.

\section{How to Reach Computer}

\section{Writers}

We welcome submissions. For detailed information, write for a Contributors' G uide (computer @computer.org) or visit our Web site: http://computer.org/pubs/computer/computer.htm.

\section{Letters to the Editor}

Please provide an e-mail address or daytime phone number with your letter.

Computer Letters

10662 Los Vaqueros Circle

Los Alamitos, CA 90720

fax (714) 821-4010

computer@computer.org

\section{On the Web}

Visit our Web site at http://computer.org for information about joining and getting involved with the Computer Society and Computer.

\section{Magazine Change of Address}

Send change-of-address requests for magazine subscriptions to address.change@ieee.org.

$\mathrm{M}$ ake sure to specify Computer.

\section{Membership Change of Address}

Send change-of-address requests for the membership directory to directory.updates@computer.org.

\section{Missing or Damaged Copies}

If you are missing an issue or received a damaged copy, contact membership@computer.org.

\section{Reprints}

We sell reprints of articles. For price information or to order, send a query to computer@computer.org or a fax to (714) 821-4010.

\section{Reprint Permission}

To obtain permission to reprint an article, contact William $\mathrm{H}$ agen, IEEE Copyrights and Trademarks $M$ anager, at whagen@ieee.org.

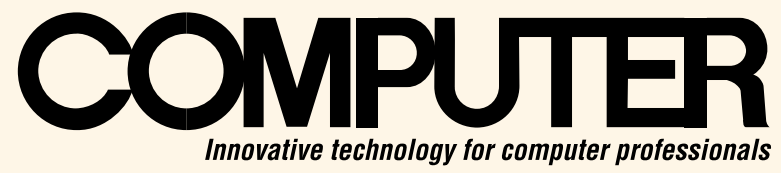

